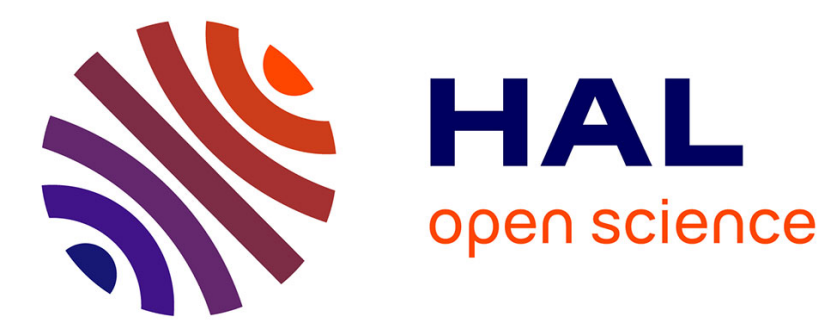

\title{
Critical or tricritical SAd-SA 2 point in a (temperature-molecular length) phase diagram?
}

F. Hardouin, M.F. Achard, Nguyen Huu Tinh, G. Sigaud

\section{To cite this version:}

F. Hardouin, M.F. Achard, Nguyen Huu Tinh, G. Sigaud. Critical or tricritical SAd-SA 2 point in a (temperature-molecular length) phase diagram?. Journal de Physique Lettres, 1985, 46 (3), pp.123-128. 10.1051/jphyslet:01985004603012300 . jpa-00232487

\section{HAL Id: jpa-00232487 https://hal.science/jpa-00232487}

Submitted on 1 Jan 1985

HAL is a multi-disciplinary open access archive for the deposit and dissemination of scientific research documents, whether they are published or not. The documents may come from teaching and research institutions in France or abroad, or from public or private research centers.
L'archive ouverte pluridisciplinaire HAL, est destinée au dépôt et à la diffusion de documents scientifiques de niveau recherche, publiés ou non, émanant des établissements d'enseignement et de recherche français ou étrangers, des laboratoires publics ou privés. 
Classification

Physics Abstracts

$61.30 \mathrm{E}-64.70 \mathrm{M}$

\title{
Critical or tricritical $\mathbf{S}_{\mathbf{A}_{d}}-\mathbf{S}_{\mathbf{A}_{2}}$ point in a (temperature-molecular length) phase diagram ?
}

\author{
F. Hardouin, M. F. Achard, Nguyen Huu Tinh and G. Sigaud \\ Centre de Recherche Paul Pascal, Université de Bordeaux I, Domaine Universitaire, \\ 33405 Talence Cedex, France
}

(Reçu le 22 octobre 1984, révisé le 26 novembre, accepté le 7 décembre 1984)

\begin{abstract}
Résumé. - A partir d'observations microscopiques, d'analyses enthalpiques différentielles et de mesures de rayons $X$, nous avons étudié la transition Smectique $A_{d}$-Smectique $A_{2}$ de sept composés de la série des 4-n alcoxyphenyl-4' cyanobenzoyloxy benzoates $\left(\mathrm{DB}_{n} \mathrm{O}\right)$. Nous montrons en particulier l'influence de la plage de température d'existence de la phase $S_{A_{d}}$ sur l'enthalpie de transition. L'ensemble des résultats suggère un comportement critique ou tricritique dans un espace thermodynamiqure température-longueur moléculaire.
\end{abstract}

Abstract. - From microscopic observations, DSC experiments and X-ray data the Smectic $A_{d}$ Smectic $A_{2}$ transition is studied in seven compounds of the 4-n alkoxy phenyl-4' cyanobenzoyloxy benzoate series $\left(\mathrm{DB}_{n} \mathrm{O}\right)$. In particular the excess enthalpy associated with this transition is found to depend on the width of the $S_{A_{d}}$ range. These results suggest either tricritical or critical behaviour in a ( $T$, molecular length) phase diagram.

\section{Introduction.}

Several kinds of smectic A phases differing in the magnitude of the layer spacing $d$ relative to the molecular length $l$ have been found [1]. In the $\mathrm{S}_{\mathrm{A}_{\mathrm{d}}}, 1<d / l<2$, whereas this ratio is nearly equal to 2 in $\mathrm{S}_{\mathrm{A}_{2}}$.

The first $\mathrm{S}_{\mathrm{A}_{d}}-\mathrm{S}_{\mathrm{A}_{2}}$ phase transition was observed in a pure long core cyano derivative, the 4-nheptyl phenyl-4'-cyanobenzoyloxy benzoate ( $\mathrm{DB}_{7}$ for short) [2]. The formula of this compound is as follows :

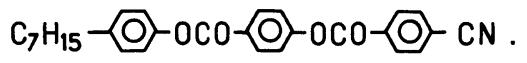

This polymorphism was ascertained in the homologues of the $\mathrm{DB}_{7}$ with longer alkyl chains $\left(\mathrm{DB}_{n}\right)[1,3]$ or alkoxy chains $\left(\mathrm{DB}_{n} \mathrm{O}\right)[1,3]$ and revealed in various other series $[4,5]$.

Referring to the earlier X-ray characterization $[1,2,4,5]$ of this transition we recall that a diffuse scattering in $S_{A_{d}}$ appears to be sharpened around $2 \pi / l$ at the $S_{A_{d}}-S_{A_{2}}$ transformation. However, the surimposition of the 002 bilayer Bragg reflexion sometimes complicate the analysis. 
Our purpose here is to specify the thermodynamic evolution of this kind of $S_{A}-S_{A}$ transition as a function of the length of the aliphatic chain varying this parameter over a large extent in the $\mathrm{DB}_{n} \mathrm{O}$ series :

$$
\mathrm{C}_{\mathrm{n}} \mathrm{H}_{2 n+1} \mathrm{O}-\mathrm{O} \text { - } 0 \mathrm{CO}-\mathrm{O}-\mathrm{OCO}-\mathrm{O}-\mathrm{CN} \text {. }
$$

\section{Experimental.}

The $\mathrm{DB}_{n} \mathrm{O}$ compounds of this study were synthesized in our chemistry laboratory. In figure 1 the transition temperatures are plotted against $n$, number of carbons in the chain, relative to the isotropic, nematic, $S_{A_{d}}$ and $S_{A_{2}}$ phases. We note that the $S_{A_{d}}$ phase becomes visible for $n>6$ and it exists within a larger and larger temperature interval as $n$ increases. These transition temperatures are obtained from microscopic observations between glass slide and cover slip. In contrast with earlier investigations of $\mathrm{DB}_{7}$ compound [2], at the transformation $\mathrm{S}_{\mathrm{A}_{2}}$ to $\mathrm{S}_{\mathrm{A}_{\mathrm{d}}}$, a textural change is detected in a planar part of the preparation as a sudden multiplication of the focal conics (Fig. 2a). Although these reversible modifications are weaker and smoother for the higher homologues, they are still observable within a $2 \mathrm{~K}$ variation (Fig. $2 \mathrm{~b}$ ).

Note that textural modifications at the $\mathrm{S}_{\mathrm{A}_{\mathrm{d}}}-\mathrm{S}_{\mathrm{A}_{2}}$ transition have been also evidenced for other compounds $[6,7]$.

The DSC traces in figure 3 were carried out by means of a DUPONT 990 apparatus with the same high sensitivity recording $\left(0.005 \mathrm{mcal} \mathrm{s}^{-1} \mathrm{in}^{-1}\right)$, the same cooling rate $\left(2^{\circ} \mathrm{min}^{-1}\right)$ and the same sample weight $(7 \mathrm{mg})$ for all the compounds $(n=7$ to 13$)$. We note that the excess of enthalpy decreases rapidly with increasing $n$. Ultimately, neither discontinuous changes in enthalpy nor continuous variations are detectable for $n=13$.

For the $n=7$ and 8 compounds the excess of enthalpy is rather large (400 and $250 \mathrm{mcal} \mathrm{g}^{-1}$ ) and could include a latent heat to the pretransitional increase of the specific heat. In contrast with these two cases, the resolution of the DSC recordings rules out the existence of a latent heat contribution for the higher homologues (Figs. 3 and 4).

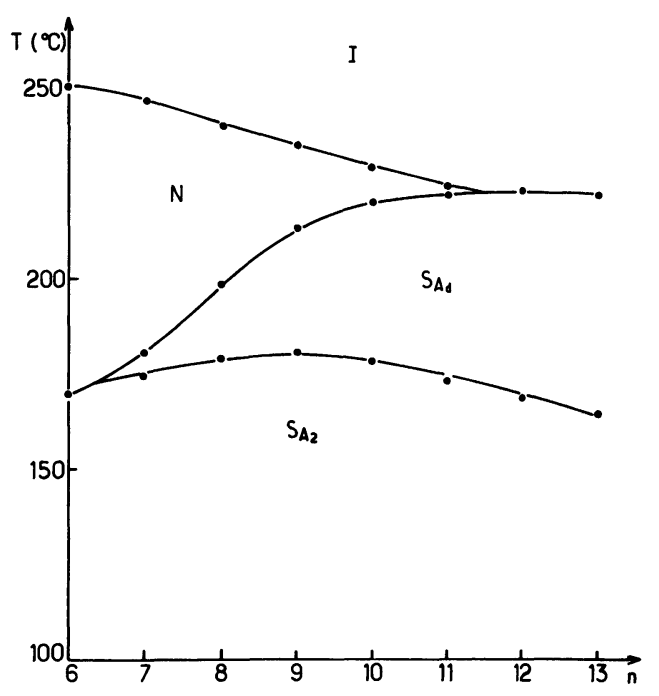

Fig. 1. - Transition temperatures versus aliphatic chain length for the $\mathrm{DB}_{n} \mathrm{O}$ series. 

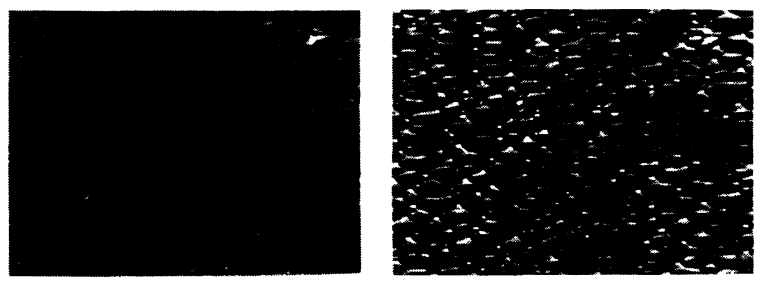

b)
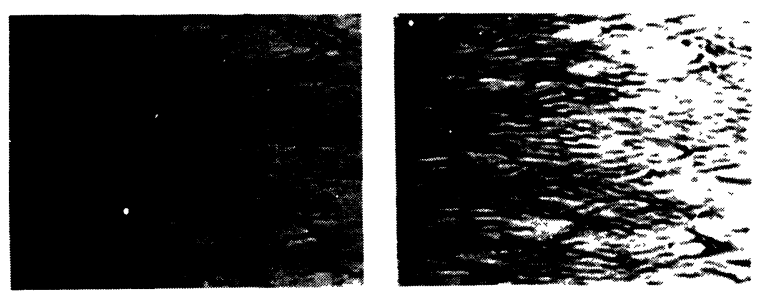

Fig. 2. - The focal conic textures of the $S_{A_{2}}$ and $S_{A_{d}}$ phases ( $\times 400$ ), (a) for $n=8:$ Smectic $A_{2}$ phase (on the left) $T=178^{\circ} \mathrm{C}$, Smectic $\mathrm{A}_{\mathrm{d}}$ phase (on the right) $T=180^{\circ} \mathrm{C}$; (b) for $n=12$ : Smectic $\mathrm{A}_{2}$ phase (on the left) $T=168^{\circ} \mathrm{C}$, Smectic $\mathrm{A}_{\mathrm{d}}$ phase (on the right) $T=170^{\circ} \mathrm{C}$.

These observations compare well with the results from small angle X-ray scattering on powder samples which yield the temperature variation of the $d / l$ ratio, where $d$ is the layer spacing and $l$ the molecular length, in the most extended conformation (SASM model) (Fig. 5).

In particular, the evolution of this parameter is quite smooth for $n \geqslant 11$ and contrary to the lower homologues, we cannot locate a $S_{A_{d}}-S_{A_{2}}$ change by this technique.

\section{Discussion.}

In our calorimetric measurements the sharp enthalpy increase at the transition for the $n=7$ compound could be interpreted as a proof of a first-order character, although the DSC method cannot really distinguish a discontinuous change in enthalpy from a rapid but continuous variation. However it should be stressed that, increasing the aliphatic chain, our results do not correspond to a decrease in the latent heat but rather to a decrease in the entropy variation due to the fluctuations.

Thus if we assume that part of the excess of enthalpy for $\mathrm{DB}_{7} \mathrm{O}$ does correspond to a latent heat, we suggest two possible meanings for our experimental results when we extend them to a temperature-molecular length space :

- either there exists a tricritical point along the $S_{A_{d}}-S_{A_{2}}$ line : this supposes that there is a hidden symmetry between $\mathrm{S}_{\mathrm{A}_{\mathrm{d}}}$ and $\mathrm{S}_{\mathrm{A}_{2}}$ [8],

- or the $S_{A_{d}}-S_{A_{2}}$ line ends somewhere at a critical point. The vicinity of such a point could induce, for the homologues with long chains, noticeable fluctuations of the specific heat yet without phase transition. Nevertheless, beyond this point, the sudden change for the focalconics should depend on kinetic effects which have not been observed. This second hypothesis implies a $S_{A_{d}}-S_{A_{2}}$ transition without any symmetry change, as theoretically predicted by $P$. Barois et al. [9]. This situation is also qualitatively described from a microscopic model considering the thermal evolution of a degree of head to head association of dimers [10]. 


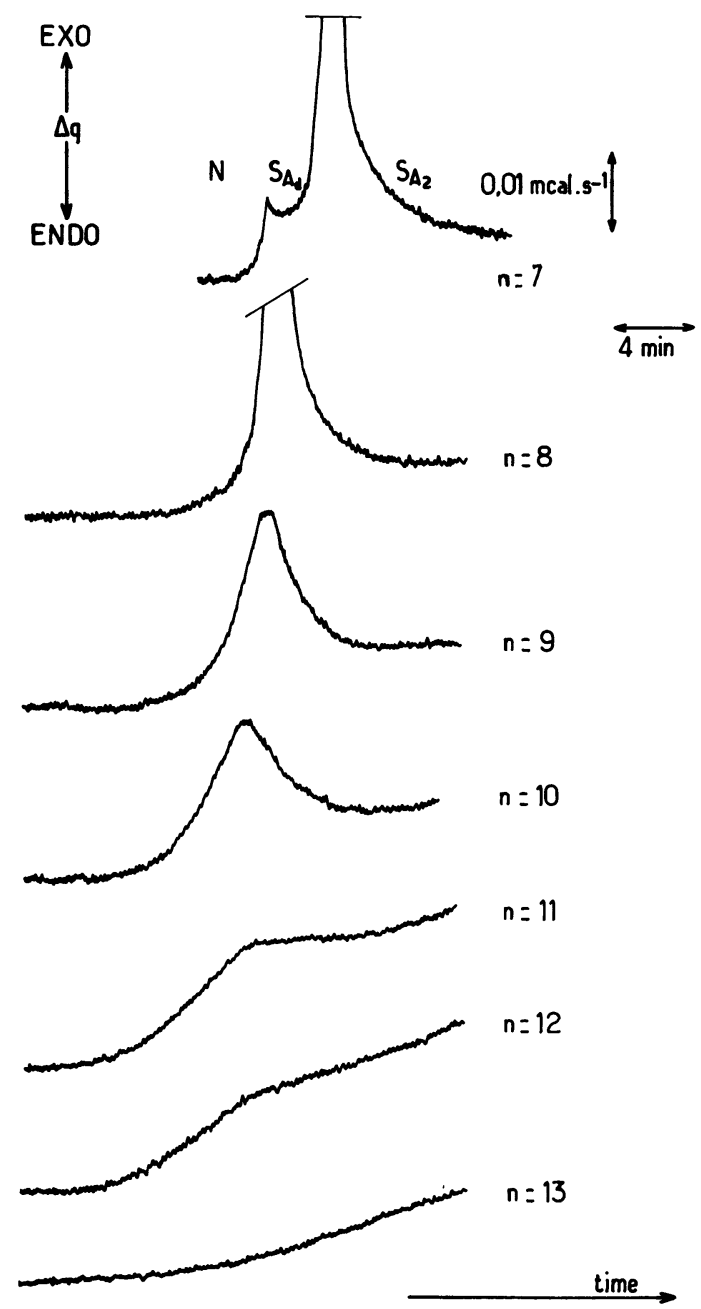

Fig. 3. - DSC cooling curves for the $\mathrm{DB}_{n} \mathrm{O}$ series in the Smectic A region (same weight : $m=7 \mathrm{mg}$ ).

None of our low resolution techniques allow us to locate this critical (or tricritical) point for a system (pure compound or binary mixture) beyond $n=7$.

As a matter of fact, high resolution experiments are clearly needed to resolve the questions of the localization and of the nature of this point.

Finally we remark that evidence is given for a strong connection between the width of the thermal range of the high temperature phase $S_{A_{d}}$ and the thermodynamical behaviour of the transition. If this evolution is confirmed in other homologous series it has to be compared with what exists for the $\mathrm{N}-\mathrm{S}_{\mathrm{A}}$ transition taking into account low resolution works [11] as well as recent high resolution results $[12,13]$. 


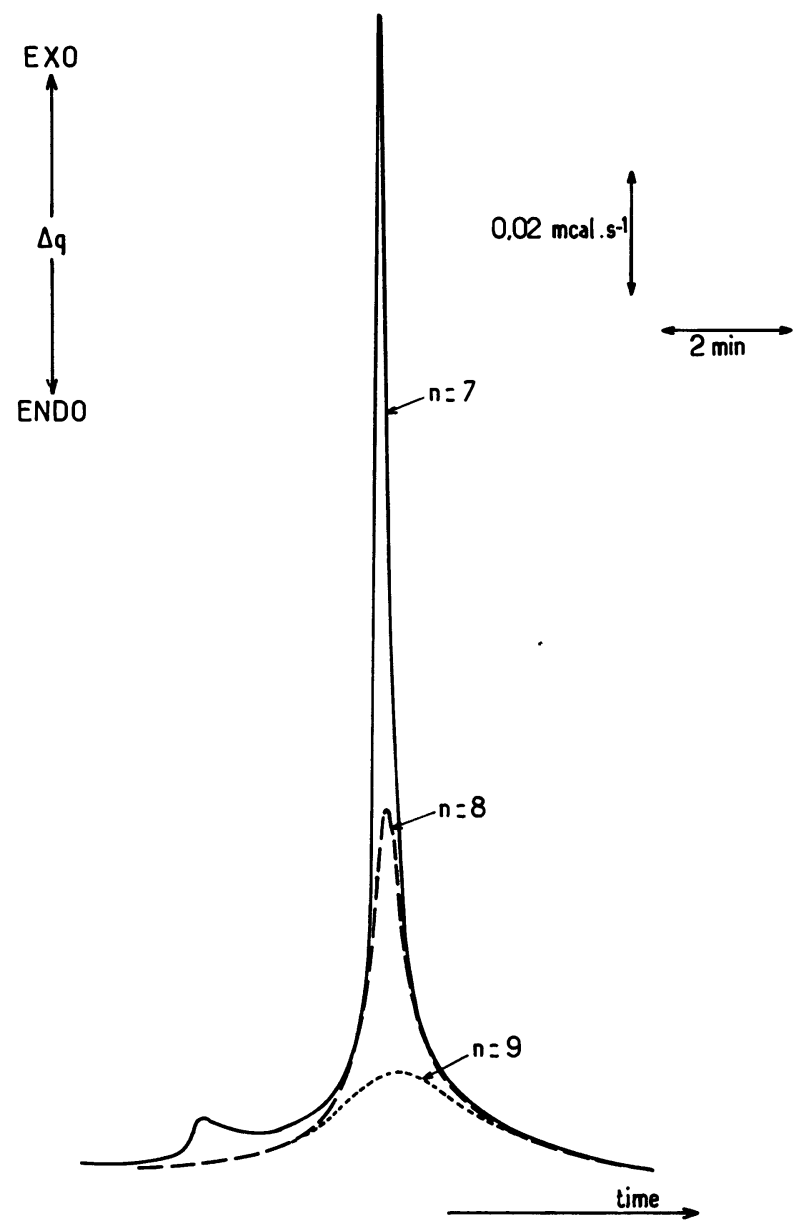

Fig. 4. - Comparative DSC recordings for the $\mathrm{S}_{\mathrm{Ad}_{\mathrm{d}}}-\mathrm{S}_{\mathrm{A}_{2}}$ transition in the compounds $n=7,8,9(m=7 \mathrm{mg})$. 


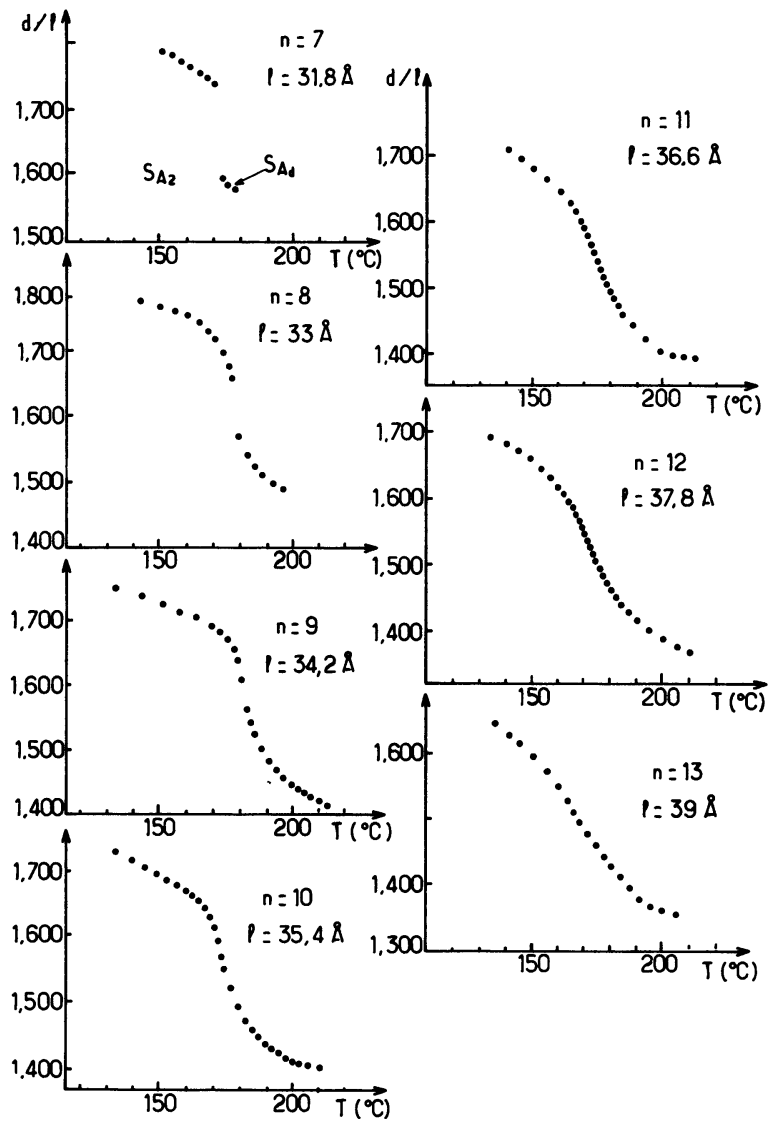

Fig. 5. - Thermal variations of the reduced layer thickness for the $\mathrm{DB}_{n} \mathrm{O}$ series, using Guinier camera (Hüber) and $\mathrm{CoK}_{\mathrm{x}_{1}}$ monochromatic radiation.

\section{References}

[1] Hardouin, F., Levelut, A. M., Achard, M. F., Sigaud, G., J. Chim. Phys. 80 (1983) 53 and the references therein.

[2] Hardouin, F., Levelut, A. M., Sigaud, G., J. Physique 42 (1981) 71.

[3] Nguyen Huu Tinh, J. Chim. Phys. 80 (1983) 83.

[4] Madhusudana, N. V., Srikanta, B. S., Subramanya Raj Urs, M., Mol. Cryst. Liq. Cryst. Lett. 82 (1982) 317.

[5] Hardouin, F., Achard, M. F., Destrade, C., Nguyen Huu Tinh, J. Physique 45 (1984) 765.

[6] Nguyen Huu Tinh, Destrade, C., Mol. Cryst. Liq. Cryst. Lett. 92 (1984) 257.

[7] Destrade, C., Hardouin, F., Nguyen HuU Tinh, Mol. Cryst. Liq. Cryst. (to be published).

[8] Longa, L., De JeU, W. H., Phys. Rev. A 28 (1983) 2380.

[9] Barois, P., Prost, J., Lubensky, T. C., J. Phys. (to be published).

[10] Guillon, D., Skoulios, A., J. Physique 45 (1984) 607.

[11] See for example : Achard, M. F., Hardouin, F., Sigaud, G., Gasparoux, H., J. Chem. Phys. 65 (1976) 1387.

[12] Kasting, G. B., Lushington, K. J., Garland, C. W., Phys. Rev. B 22 (1980) 321.

[13] Thoen, J., Marynissen, H., Van Dael, W., Phys. Rev. Lett. 52 (1984) 204. 